\section{INFLUÊNCIA \\ DA INESPECÍFICA COM O BCG SOBRE A SUSCETIBILIDADE DO HAMSTER À INFECÇĀO EXPERIMENTAL POR Leptospira interrogans SOROTIPO pomona *}

\section{CLEBERT JOSÉ ALVES}

Professor Assistente

Universidade Federal da Paraíba

SILVIO ARRUDA VASCONCELLOS

Professor Associado

Faculdade de Medicina Veterinária e Zootecnia da USP

\section{CLAUDIO ROBERTO DE ALMEIDA CAMARGO \\ Pesquisador Científico Instituto Butantan}

\section{NICODEMOS ALVES DE MACEDO \\ Professor Assistente}

Universidade Federal do Piauí

ZENAIDE MARLA DE MORAIS

Tecnico Especializado

Faculdade de Medicina Veterinária e Zootecnia da USP

\section{RODOLFO NÜRMBERGER JUNIOR}

Professor Doutor

Faculdade de Medicina Veterinária e Zootecnia da USP

SONLA REGINA PINHEIRO

Professor Assistente

Faculdade de Medicina Veterinaria e Zootecnia da USP

\section{JOSÉ SOARES FERREIRA NETO}

Professor Doutor

Faculdade de Medicina Veterinária e Zootecnia da USP

ALVES, C.J.; VASCONCELLOS, S.A; CAMARGO, C.R.A; MACEDO, N.A.; MORAIS. ZM.; NÜRMBERGER JUNIOR, R.; PINHEIRO, S.R.; FERREIRA NETO, J.S. Influência da estimulaçáo inespecífica $\infty \mathrm{m}$ ○ BCG sobre a suscetibilidade do hamster à infecçăo experimental por Leptospira Interrogans sorotipo pomona. Braz. J. vet Res. anim. Scl., Såo Paulo, v.29, n.2, p.193-9, 1992.

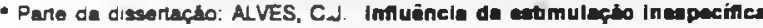
com a BCQ sobre a suscatbilldede do hamets: I Infeçio experimenta por Leptopira Intarrogana sorotapo pomona Sho Paulo, 1991 Discertaçio (Mesirado). Faculdade de Medicina Veleninária e Zootecnia, Unnersidade de Sa Paulo
}

RESUMO: Foi investigada a influencia do BCG sobre o grau de resistência apresentado pelo namster à infecçăo experimental por leptospiras. Foram utilizados 48 animais (machos com peso entre 60 a 80 gramas) dos quais 23 tratados com o BCG (duas aplicações de $0.5 \mathrm{ml}$, via intraperitonial com intervalo de sete dias) e 25 tratados com placebo (meio de Souton) nas mesmas condiç̧̋es referidas. No terceiro dia após a segunda dose do imunomodulador ou placebo, os animais foram experimentalmente infectados. via intraperitonial, com um inóculo de $0,5 \mathrm{ml}$ de uma cultura de $L$ interrogans sorotipo pomona. Os animais ficaram em observaçāo durante 21 dias e os que apresentaram sinais da doença foram sacrificados em fase agônica. A esse tempo foi realizada a colheita de materiais destinados a confirmar o estabelecimento da infeccăo experimental, atraves de métodos diretos (visualização em campo escuro e/ou cultura em meio de Fletcher) e indiretos (reaçăo de soroaglutinaçảo microscópica). As proporçós de animais mortos por leptospirose dentre os infectados foram de $0 / 23$ $(0,00 \%)$ de $20 / 25(80,00 \%)$, respectivamente, para o grupo tratado com o BCG e o grupo placebo.

UNITERMOS: Loptospirose; Leptospira interrogans; BCG

\section{INTRODUÇĀO}

Dentre os animais de laboratório empregados como sistema biológico para o estudo da leptospirose, o hamster (Mesocricetus auratus) tem sido a espécie de escolha para a reproduçăo da tase aguda da infecçăo, pois mostra-se altamente suscetivel a diversos sorotipos de Leptospira interrogans, entre os quais se destacam o pomona $1,10,13$ - o canicola 7,15. No entanto, torna-se necessário a descoberta de uma forma de reprodução experımental da condiçăo de portador de leptospiras visto que, em surtos de leptospirose nos rebanhos animais de interesse economico, e frequiente a existência de individuos que apresentam uma fase aguda assintomática, entrando no período de leptospirúria sem ter acusado a presença de anticorpos 22

A despeito da existencia de um grande número de investigaçōes sobre a influência do BCG em processos infecciosos provocados por patógenos intracelulares, poucos são os estudos relativos ao uso deste imunomodulador 21 sobre a patogenia de infecções induzidas por agentes extracolulares como as leptospiras. destacando-se a constatação de ADLER e FAINE ${ }^{2}$ (1977) em camundongos, relatando a nāo influência do BCG no curso da intecçăo por leptospiras em camundongos normais imunossuprimidos e a de TU et al. ${ }^{19}$ (1982) que concluiram ser a estimulaçăa inespecífica de macrófagos com o BCG incapaz de reverter o efeito letal da infeccảo em camundongos. No entanto, o insucesso destes autores pode 
Intuincie de astomuectio inaspecitice com o BCC

ser atribuido ao esquema adotado para as aplicaçøes do BCG que incluiu uma única dose do produto e que, segundo ALEXANDER ${ }^{4}$ (1973), nảo possibilitaria que macrófagos armados passassem a condição de ativados.

Portanto. delineou-se o presente estudo cujo objetivo toi verificar a influência da estimulação inespecífica com BCG sobre a suscetibilidade do namster à infecçăo experimental por $L$ interrogans sorotipo pomona.

\section{MATERIAL E MÉTODO}

Foram utilizados 58 hamsters (Mesocricetus auratus) jovens, machos, com peso variando entre 60 a 80 gramas, distribuídos em caixas plásticas forradas com maravalha, em grupos de no máximo três individuos.

O inóculo utilizado para provocar a infecçăo foi a estipe virulenta de $L$ interrogans sorotipo pomona, tipificada pela prova de absorçåo de aglutininas ${ }^{14}$ e conservada em nitrogênio líquido a $196{ }^{\circ} \mathrm{C}$ negativos ${ }^{3}$. No momento da utilizaçào as ampolas foram descongeladas e o seu conteúdo submetido a um exame microscópico para a verificaçăo da presença de leptospiras ativas, sendo posteriormente feita a semeadura em tubos com o meio semi-sólido de Fletcher. Após dez dias as culturas foram submetidas a nova avaliaçăo em microscopia de campo escuro, e a contagem de leptospiras ativas em cinco campos microscópicos apresentou o valor médio de 31,5 microrganismos por campo. Cada animal utilizado recebeu - volume de $0,5 \mathrm{ml}$ do respectivo inóculo, através da via intraperitoneal

Utilizou-se, ainda, como inoculo, a substância OncoBCG oral ${ }^{18}$, bacilo de Calmette-Gúrin, cepa Moreau na concentraçăo de $100 \mathrm{mg} / \mathrm{ml} \mathrm{3,6} \mathrm{a} 5,7 \times 10^{7}$, bacilos viáveis por $\mathrm{ml}$. Cada animal utilizado recebeu duas aplicaços de $0.5 \mathrm{ml}$ de BCG, através da via intraperitoneal, com intervalo de sete dias. No terceiro dia após a segunda dose do BCG ou placebo, os animais foram experimentalmente infectados, via intraperitoneal, $\infty \mathrm{m} 0,5 \mathrm{ml}$ de cultura de $L$ interrogans sorotipo pomona.

O diluente adotado para a preparaçăo das suspensơos de brgăos e para a diluiçāo dos soros e antígenos foi representado pela soluçăo tamponada de Sorensen 14.

O meio de Souton foi preparado e utilizado conforme indicado por BRAGA 6 (1941).

A técnica de isolamento de leptospiras, em meio de cultura, foi executada apos o processamento de uma suspensảo de tecido renal a $10 \%$ (peso/volume), sendo preparadas duas diluiçóes seriadas de razảo dez, de tal modo a fornecer as concentraçoes finais de 10, 1,0 e 0,1\% (peso/volume). Cada uma destas concentraçós foi semeada em dois tubos contendo o meio de Fetcher ${ }^{14}$, os quais foram incubados a temperatura de $28{ }^{\circ} \mathrm{C}$ durante oito semanas, realizando-se leituras em microscopia de campo escuro a cada três dias, nas duas primeiras semanas e semanalmente, nas subsequentes ${ }^{14}$.

A reaçăo de soroaglutinaçảo microscópica foi utilizada para avaliaçảo dos niveis de imunidade humoral antileptospira nos animais experimentalmente infectados. Para a execuçăo desta técnica, os antigenos foram representados por culturas de leptospiras vivas. em meio EMJH, enriquecido com L-asparagina, soro estéril de coelho e da solução de cálcio e magnésio 20

A fixaçào dos fragmentos de fígado, baço e rins for realizada pela imersão de tais materiais em soluçāo de formalina a 10\%. Após a fixação, os fragmentos foram incluídos em blocos de parafina $\theta$, a seguir, foram realizados os cortes em micrótomo e coloraçăa pelo método de hematoxilina-osina 5 .

Os 58 hamsters machos foram aleatoriamente divididos em grupos designados pelas letras " $A$ " e "C", contendo cada um deles quatro animais e os grupos " $B$ " e "D", com 25 animais cada.

Os animais foram mantidos em infectório com observação a cada 12 horas para a constataçăo de alteraços clínicas. Os individuos que apresentaram sinais clínicos de leptospirose foram sacrificados na fase agônica da doença, sendo os demais sacrificados no $21^{2}$ dia posinoculaçăo.

A análise estatística, adotada para a interpretaçăo dos resultados obtidos e a comprovação de hipótese de trabalho, aplicou o teste năo paramétrico de Qui quadrado 17 .

\section{RESULTADOS}

Todos os animais do grupo "A", tratados inicialmente com BCG - posteriormente com placebo, apresentaram granulomas induzidos pelo M. bovis no figado, baço e rim, caracterizados basicamente pela presença de células epitelibides, circundando os bacilos da tuberculose, sendo que esta reaçăo em órgảos como fígado e baço foi mais frequiente do que nos rins.

Os animais do grupo " $\mathrm{C}$ ", tratados apenas com placebo, simulando tanto a aplicaçăo do BCG, quanto de leptospiras, nảo apresentaram nenhuma alteração histológica nos três tipos de orgăos trabalnados (fígado, baço rim).

A Tab. 1 apresenta os resultados dos exames conduzidos nos animais do grupo "B", tratados inicialmente com duas doses de BCG e posteriormente infectados com diferentes concentraçbes de $L$ interrogans sorotipo pomona. Persistindo na apresentaçăo da Tab. 1, pode-se constatar que, durante os 21 dias de observaçáo após a inoculaçăo de leptospiras, os 23 componentes do grupo " $B$ " se mantiveram clinicamente normais e a confirmaçăo da infecçăo por leptospiras só foi obtida nos exames realizados após o sacrifício, salientando-se a demonstraçăo da 
presença dos microrganismos nos cultivos de tecido renal de todos os espécimes trabalhados $(23 / 23)$ e a conversão sorológica em $91.3 \%$ dos casos (21/23), ressaltando-se a existência de dois animais (números 19 e 22) com resultado negativo na prova sorológica e positivo na cultura de tecido renal. Todos os animais do grupo " $B$ " apresentaram lesōes no figado. baço e rim, segundo a tecnica de coloraçăo da hematoxilina e oosina, caracterizadas por: Rim - quadro evolutivo de nefrite do tipo sub-agudo com baixo índice necrótico/congestivo e presença de infiltrado inflamatório do tipo mononuclear; Fígado - quadro congestivo de pequena intensidade, vacuolização dos hepatócitos e distribuição necrótica médio-zonal; Baço - necrose da polpa vermelha e hiperplasia dos folículos linfóides.

A Tab. 2 apresenta os resultados dos exames obtidos com os animais do grupo " $\mathrm{D}$ ". Analisando-se esta tabela, observa-se que os 25 animais nảo tratados com o BCG apresentaram um comportarnento totalmente diferente do grupo "B". Os 25 animais do grupo "D" receberam duas doses de placebo (meio de Souton) $\theta$, posteriormente, foram infectados experimentalmente com L interrogans sorotipo pomona. A ovolução do quadro clínico dos animais revelou que 20 dos 25 desenvolveram sintomas característicos de leptospiroso, chegando a b́bito ou sendo sacrificados em fase agônica entre o $5^{\circ}$ e $\circ 8^{\circ}$ dia após inoculaçăo. Os animais de número $43,50,55,57$ e 58 conseguiram superar a fase aguda da doença e se encontravam vivos nos $21^{\circ}$ dia após inoculaçăo, quando foram sacrificados. Os resultados dos exames laboratoriais dos 25 animais do grupo " $D$ " revelam que, enquanto foram isoladas leptospiras em todos os materiais trabalhados, as aglutininas anti-leptospira so foram demonstradas om dois dos 25 animais examinados.

As alteraçóes estruturais observadas nos cortes histológicos dos órgảos de todos os animais do grupo "D" foram representadas por Pim: hemorragias intensas ao nivel intersticial, tanto na regiāo cortical quanto na medular, necrose de túbulos e glomérulos, hemossiderose e calcificaçảo de túbulos; Figado: severa congestão $\theta$ presença de áreas necróticas com distribuiçăo módio-zonal, desorganizaçéno trabecular com isolamento dos hepatócitos, sinais de destruiçăo dos sinusóides com degradaçăo dos eritrócitos e liberaçăo do ferro no meio (hemossiderose); Baço: áreas necróticas da polpa vermelha e degeneraçăo eritrocitária, folículos com pouca proliferaçăo dos centros germinativos

\section{DISCUSSÃO}

A comparação dos valores encontrados nos animais dos grupos " $A$ " $\theta$ " $C$ " evidencia a auséncia de alteraçóes estruturais atribuiveis a $L$ interrogans sorotipo pomona, nos orgãos dos animais dos grupos controles " $\mathrm{A}$ " \& " $\mathrm{C}$ " e a presença de granulomas atribuidos ao BCG no figado, baço e rim dos animais do grupo controle "A". A presença de granulomas induzidos pelo BCG nas visceras dos hamsters inoculados com este microrganismo concorda com as afirmaçóes de MITCHELL et al. ${ }^{12}$ (1975), que observaram estes achados em camundongos inoculados com o BCG.

$A$ análise dos resultados apresentados na Tab. 1 salienta que os animais inoculados com o BCG conseguiram superar a fase aguda da leptospirose e atıngiram o $21^{\circ}$ dia pós-inoculação vivos, sem terem exteriorizado nenhum sintoma clínico da infecçảo por $L$ interrogans. Como a imunidade desencadeada pelo BCG é do tipo celular ${ }^{11}$ e a resposta imune envolvida na fase aguda da leptospirose $\theta$ do tipo humoral 9 concluiu-se que a estimulaçăo inespecífica traduzida pela ativaçăo dos macrófagos deve ter criado condiçóes para que os anticorpos circulantes pudessem ser produzidos mais precocemente. Saliente-se que, neste particular, SCHELL et al. ${ }^{16}$ (1983), afirmaram que os macrólagos ativados possuem acentuadas propriedades fagocitárias e bactericidas, nảo somente contra organismos infectantes. mas também contra organismos filogeneticamente distantes. De fato, a estimulaçåa inespecífica induzida pelo BCG, com a ativaçăo de macrófegos, parece exercer um importante papel na fase aguda da leptospirose, principalmente quando se considera que segundo TU et al. 19 (1982), as colulas fagocitarias podem influenciar a produçăo precoce dos anticorpos circulantes, importante mecanismo de defesa do hospedeiro contra patógenos extracelulares.

Os resultados nas Tab. 1 e 2 salientam a marcante influencia do tratamento com o BCG sobre a suscetibilidade do hamster à infecçåo por leptospiras, no entanto, este tipo de comportamento nảo foi obtido por ADLER e FANE 2 (1977) e por TU et al. 19 (1982) que veriticaram a nảo influência do BCG sobre o curso da infecçăo por leptospiras em camundongos; poróm, cumpre salientar que estes autores utilizaram apenas uma dose de BCG $\theta$ estabeleceram a infecçăo com leptospiras três semanas após o imunomodulador, tase em que, segundo ALEXANDER 4 (1973), já desapareceu a característica de ativaçăo inespecífica dos macrófagos.

Observanda-se os resultados dos cultivos de tecido renal apresentados na Tab. 1, verifica-se que no $21^{9}$ dia pósinoculaçăo os $\mathbf{2 3}$ sobreviventes do grupo B encontravam-se na condiçăo de portadores renais, demonstrando que a inoculaçăo do BCG foi capaz de impedir o estabelecimento do quadro agudo da infecçăo, mas năo a colonizaçăo dos túbulos renais dos animais trabałhados, o que está de acordo com os resultados obtidos por FANE et al. ${ }^{9}$ (1974), om seus estudos sobre a imunidade para leptospirose em camundongos.

Os animais de número 19, 22, 43, 57 e 58 (Tab. 1 e 2) não reagentes à prova de soroaglutinação microscópica e positivos na cultura do tecido renal caracterizam uma situação de grande significado epidemiológico que já foi constatada em condiçōes naturais $8,14,22$ 
Infuinces de womuef bo inapecifice cam o BCG.

As ateracóes estruturais verificadas nos animais do grupo "D", năo inoculados com ○ BCG, săo do tipo degenerativo, com severa vacuolizaçăo e necrose do epitélio tubular, acrescida de infiltraçāo mononuclear, características de um quadro de nefrite intersticial com evoluçảo subaguda.

As informaçóes contidas na Tab. 2 traduzem o comportamento dos animais do grupo "D", não sensibilizado com o BCG. Os dados apresentados revelam a evolução aguda da leptospırose onde $80 \%$ (20/25) dos animais morreram entre o $5^{\circ}$ o $8^{\circ}$ dia da infecção, após terem apresentado os sinais clínicos da doença. Saliente-se que esta marcante evoluçảo observada no grupo " $D$ ", pouco influenciada pela variaçảo na concentraçăo de leptospiras no inóculo, 6 completamente contrastada pelo comportamento dos animas do grupo "B" (tratados pelo BCG), com $100 \%$ de sobreviventes no $21^{\circ}$ dia pósinoculacăo de leptospiras, dos quais 91,30\% (21/23) mostraram elevados niveis de anticorpos aglutinantes antileptospira.

O emprego do teste de Qui quadrado para a comparaço nos grupos "B" e "D", com vajores respectivos de 23/23 e 5/25, possibilitou a aceitaçăo da existência de uma major resistoncia a leptospirose nos animais tratados pelo BCG $(p<0,001)$

\section{CONCLUSAO}

Hamsters machos, submetidos a duas aplicaçōes do BCG (via intraperitonial, com sete dias de intervalo) resistiram à inoculaçảo com $L$ interrogans sorotipo pomona com o estabelecimento de leptospirúria em ausencia de sinais clínicos da leptospirose.

ALVES, C.J.; VASCONCELIOS, S.A; CAMARGO, C.R.A; MACEDO, N.A; MORAS, ZM; NÜMBERGER JUNIOR, R.; PINHEIRO, S.R.; FERREIRA NETO. J.S. Influence of BCG inespecific stimulation on the hamsters susceptibility to the experimental infection L interrogans serovar pomona. Braz. J. vet Res. anim. Scl, São Paulo, v.29, n.2, p. 193-9, 1992.

SUMMARY: The influence of BCG on the resistance of hamsters experimentally infected with Leptaspira interrogans serovar pomona was investigated. Forty-eight young male hamsters were used as the follow: 23 of them have administered two intraperitoneal dosis of BCG with seven days of interval; the remaining 25 were treated with placebo (Souton solution) in the same way as in the BCG treatment. On the third day atter the second BCG or placebo administration, each animal was inoculated with $0.5 \mathrm{ml}$ of a suspension of $L$ pomona through the intraperitoneal route. The animals were observed foi signs and symptoms of leptospirosis during a period of 21 days and those in the agonic state of disease were killed and their kidney and serum samples were taken for the demonstration of antibodies and leptospiroses, by means of serum agglutination test and by the direct culture of kidney fragments. All of the survivors were killed at the $21^{\text {st }}$ day post infection and evaluated for antibodies an leptospires, as described above. For the BCG treated group, no death was recorded $(0 / 23$ or $0,00 \%)$ whereas in the control group $80 \%$ of deaths $(20 / 25)$ were observed

UNITERMS: Loptospirosis; Leptospira Interrogans; BCG

\section{REFERENCLAS BIBLIOGRAFICAS}

01-ABDU, F.; SLEIGHT, S.D. Pathology of Loptospira pomona infection in hamsters. Cornell Vet, v.55, p.74-86, 1965.

O2-ADLER, B.; FANE, S. Host immunological mechanisms in the resistance of mice to leptospiral infections. Infect Immun., v.17, p.67-2, 1977

03-ALEXANDER, A.D.; LESSEL, E.F.; EVANS, LB.; FRANCK E.; GREEND, S.S. Preservation of leptospiras by liquid nitrogen refrigeration. Int J. systern. Bacteriol., v.22, p.165-9, 1972.

O4-ALEXANDER, P. Activated macrophages and the antitumor action of BCG. Nat Cancer Inst. Monogr. v.39, p.127-36, 1973.

05-BEHMER, O.A; TOLOSA, E.M.C.; FREITAS NETO, A.C. Manual de tócnicas para histologia normal e patologia. Såo Paulo, EDART/EDUSP, 1976.

O6-BRAGA, A Soros, vecinas, alórgenos e Imunógenos Rio de Janeiro, Serviço de Informaçảo Agricola, Ministéio da Agricultura, 1941. p.83-110: Sobre a titulagem da tuberculina.

07-BRUNNER, K.T. Notes on Leptospira canicola in hamsters (Mesocricetus auratus). Pathogenesis, treatment and immunity. Calif. Vet., v.1, n.6. p.18-20, 41,1948 


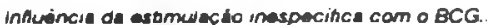

OB-FAINE, S. Guidelines for the control of leptospirosis Geneva, World Health Organization, 1982. WHO off set Publication. 67)

O9FAINE, S: ADLER, B: RUTA, G.A.A. Mechanisms of immunity to leptospirosis. Aust J. exp. Biol. med. Sci, v.52. p.301-10, 1974.

10-HAMDY, A.H.: FERGUSON, L.C. Virulence of Leptospira pomona in hamsters and cattle. Amer. J. vet Res., v.18, p.681-4, 1957

11-MACKANESS, G.B.; AUCLAR, D.J.; LAGRANGE, P.H. Immunopotentiation with BCG. I. Immune response to different strains and preparations. J. Nat Cancer Inst. v.51, p.1655-67, 1973.

12-MITCHELL, S.M.; MOKYR, M.B.; KAHANEI. Stimulation of lymphoid cells by components of BCG. J. Nat Cancer Inst, v.55, p. 1337-43, 1975.

13-SANGER, V.L.; HAMDY, A.H.; FIZETTE, W.B.; BOHL. E.H.; FERGUSON, LC. Leptospire pomona infection in hamsters. Cornell Vot., v.51, p.489-98, 1961.

14SANTA ROSA, C.A. Diagnóstico laboratorial das leptospirosis. Rev. Microbiol., v.1, p.97-109, 1970.

15-SAPP, W.J.; SIDDIOUE, I.H.; WILLIAMS, C.S.; GRAHAM, T. Histopathologic evaluation of livers of pregnant hamsters infected with Leptospira canicole. Amer. J. vet Res., v.41, p. 1283-92, 1980.
16-SCHELL, F.R.; AZADEGAN, A.A; NITSKANSKY, S.G.; LEFROCK, J.L. Effect of local and sistemic macrophage activation in hamsters on infection with Treponema pertenue and Treponema pallidum. Bosnia A. J. Reticuloendothel. Soc., v.33, p.231-8, 1983.

17.SIEGEL. S. Estatistica nào paramétrica. São Paulo, Mac Graw-Hill do Brasil, 1975.

18-SOERENSE, B.; PEREIRA, M.M.M.; GILDA, AS. YAMAGUCHI, I.K; SCALABRELLI, R. Normas para a preparação do BCG oral destinado ao tratamento coadjuvante das neoplasias. Vacinas e Soros, n.1, p.6470, 1985

19-TU, V.; ADLER, B.; FANE, S. The role of macrophages in the protection of mice against leptospirosis "in vitro" and "in vivo" studies. Pathology, v.14, p.463-8, 1982.

20-TURNER, L.H. Leptospirosis. III. Maintenance isolation and demonstration of leptospiras. Trans. Roy. Soc. Trop. Mod. Hyg., v.64, p.623-46, 1970.

21-VANSELOW, B.A. The application of adjuvants to veterinary medicine. Vet Bull., v.57, p.881-96, 1987

22-VASCONCELLOS, S.A. O papel dos reservatórios na manutençăo de leptospirose na natureza. Comun. cient Fac. Med. Vot Zootec. Univ. S. Paulo, v.11, p. 17-24, 1987.

Recebido para publiceção em 21/11/91 Aprovado para publicaçào em 21/05/92 
TABELA 1 - Hamsters do grupo "B" segundo o número de identificaçăo, a evoluçăo clínica e os resultados dos exames laboratoriais. São Paulo, 1991.

\begin{tabular}{|c|c|c|c|c|c|c|}
\hline \multirow{3}{*}{$\begin{array}{l}\text { N2 DE } \\
\text { IDENTI- } \\
\text { FICACAO }\end{array}$} & \multirow{3}{*}{$\begin{array}{l}\text { DILUICAO } \\
\text { INOCULO"W" } \\
\text { L interrogans } \\
\text { sorot ipo pomona }\end{array}$} & \multicolumn{3}{|c|}{ EVOLUCAO CLINICA } & \multicolumn{2}{|c|}{ RESULTADOS } \\
\hline & & $\ldots$ & $\ldots \ldots \ldots$ & n. & . & $\ldots$ \\
\hline & & $\begin{array}{l}\text { Data Pi } \\
\text { óbito }\end{array}$ & $\begin{array}{l}\text { Data Pi } \\
\text { Sacrifício }\end{array}$ & $\begin{array}{l}\text { Sintomas de } \\
\text { Leptospirose }\end{array}$ & $\begin{array}{l}\text { Pesquisa } \\
\text { do agente } \\
\text { Cultura/Rim }\end{array}$ & $\begin{array}{l}\text { Pesquisa } \\
\text { Anticorpos } \\
\text { saM L } \\
\text { Interrogans } \\
\text { sorotipo } \\
\text { pomona }\end{array}$ \\
\hline 5 & $10^{-0,000}$ & $\ldots$ & 29 & N & $\mathbf{P}$ & $3.200 *$ \\
\hline 6 & $10^{-0,000}$ & $\ldots$ & 21 & N & $\mathbf{P}$ & 200 \\
\hline 8 & $10^{-0,000}$ & $\ldots$ & 21 & N & $\mathbf{P}$ & 6.400 \\
\hline 9 & $10^{-0,000}$ & $\ldots$ & 21 & N & $\mathbf{P}$ & 6.400 \\
\hline 10 & $10^{-0,000}$ & $\ldots$ & 21 & N & $\mathbf{P}$ & 6.400 \\
\hline 11 & $10^{-0,3010}$ & $\ldots$ & 21 & N & $\mathbf{P}$ & 3.200 \\
\hline 12 & $10^{-0,3010}$ & $\ldots$ & 21 & H & $\mathbf{P}$ & 6.400 \\
\hline 13 & $10^{-0,3010}$ & $\ldots$ & 21 & M & $\mathbf{p}$ & 6.400 \\
\hline 14 & $10^{-0,3010}$ & $\ldots$ & 21 & N & $\mathbf{P}$ & 3.200 \\
\hline 15 & $10^{-0,6021}$ & $\ldots$ & 21 & N & $P$ & 12.800 \\
\hline 16 & $10^{-0}-6021$ & $\ldots$ & 29 & N & $\mathbf{P}$ & 1.600 \\
\hline 18 & $10^{-0,6021}$ & $\ldots$ & 21 & N & $\mathbf{P}$ & 6.400 \\
\hline 19 & $10^{-0,6021}$ & ... & 21 & N & $\mathbf{P}$ & 0 \\
\hline 20 & $10^{-0,9031}$ & $\ldots$ & 21 & N & $\mathbf{P}$ & 3.200 \\
\hline 21 & $10^{-0,9031}$ & $\ldots$ & 21 & N & $\mathbf{P}$ & 3.200 \\
\hline 22 & $10^{-0,9031}$ & $\ldots$ & 21 & N & $\mathbf{P}$ & 0 \\
\hline 23 & $10^{-0,9031}$ & $\ldots$ & 21 & N & $\mathbf{P}$ & 3.200 \\
\hline 24 & $10^{-0,9031}$ & $\ldots$ & 21 & N & $\mathbf{P}$ & 6.400 \\
\hline 25 & $10^{-0,2041}$ & $\ldots$ & 21 & N & $\mathbf{P}$ & 3.200 \\
\hline 26 & $10^{-1,2041}$ & $\ldots$ & 21 & N & $P$ & 3.200 \\
\hline 27 & $10^{-1}, 2041$ & $\ldots$ & 21 & N & $P$ & 3.200 \\
\hline 28 & $10^{-1,2041}$ & $\ldots$ & 21 & N & $\mathbf{P}$ & 3.200 \\
\hline 29 & $10^{-1,2041}$ & $\ldots$ & 21 & $N$ & $P$ & 3.200 \\
\hline TOTAL & $\ldots$ & $0 / 23^{\star}$ & $23 / 23$ & $0 / 23$ & $23 / 23$ & $21 / 23$ \\
\hline
\end{tabular}

GRUPO EXPERIMENTAL B = Grupo de 23 animais tratados $\infty \mathrm{m}$ BCG e posteriormente infectados $\infty \mathrm{m} L$ interrogans sorotipo pomona; $\mathrm{Pi}$ = Pós-inoculaģăo de $\mathrm{L}$ Interrogans; SAM = Soroaglutinaçăo microscobica: $\mathrm{P}$ = Positivo; $N=$ Nogativo; $\ldots$ = Dado năo disponível; $"=$ Número de animais positivos/Número de animais examinados: = Reciproca da major diluiçăo do soro com $50 \%$ de leptospiras aglutinadas por campo microscópico; "t=" = Número médio de leptospiras por campo microscópico no inóculo puro = 31,5. 
TABELA 2 - Hamsters do grupo "D" segundo o número de identificaçăo. A diluição do inóculo. A evoluçāo clínica e os resultados dos exames laboratoriais. Sảo Paulo, 1991.

\begin{tabular}{|c|c|c|c|c|c|c|}
\hline \multirow{2}{*}{$\begin{array}{l}\text { H D DE } \\
\text { I DENTI - }\end{array}$} & DILUICCAOO & \multicolumn{3}{|c|}{ EVOLUCAAO CLINICA } & \multicolumn{2}{|c|}{ RESUL TADOS } \\
\hline & INOCCULOむ屯 & (n) & ............ & …........... & 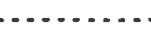 & $\ldots \ldots$ \\
\hline & $L$ interrogans & Data Pi & Data $\mathrm{Pi}$ & sintomas de & Pesquisa & Pesquisa \\
\hline & sorot ipo pomona & óbito & Sacrificio & Leptospirose & do agente & Anticorpos \\
\hline & & & & & Cultura/ & SAM L \\
\hline & & & & & Rim & interrogans \\
\hline & & & & & & $\begin{array}{l}\text { sorotipo } \\
\text { pomona }\end{array}$ \\
\hline
\end{tabular}

\begin{tabular}{|c|c|c|c|c|c|c|}
\hline 34 & $10-0,000$ & 5 & $\ldots$ & $P$ & $\mathbf{P}$ & $0^{\star \star *}$ \\
\hline 35 & $10 \cdot 0,000$ & 5 & $\cdots$ & $P$ & $\mathbf{P}$ & 0 \\
\hline 36 & $10^{-0,000}$ & 5 & $\ldots$ & $\mathbf{P}$ & $\mathbf{P}$ & 0 \\
\hline 37 & $10^{-0,000}$ & 5 & $\ldots$ & $\mathbf{P}$ & $P$ & 0 \\
\hline 38 & $10^{-0,000}$ & 5 & ... & $P$ & $P$ & 0 \\
\hline 39 & $10^{-0,3010}$ & 5 & $\ldots$ & $P$ & $P$ & 0 \\
\hline 40 & $10^{-0,3010}$ & 5 & $\ldots$ & $\mathbf{P}$ & $\mathbf{P}$ & 0 \\
\hline 41 & $10^{-0,3010}$ & 8 & ... & $P$ & $P$ & 0 \\
\hline 42 & $10^{-0,3010}$ & 8 & $\ldots$ & $P$ & $P$ & 0 \\
\hline 43 & $10^{-0,3010}$ & $\ldots$ & 29 & N & $P$ & 0 \\
\hline 44 & $10^{-0,6021}$ & 5 & $\ldots$ & $\mathbf{P}$ & $\mathbf{P}$ & 0 \\
\hline 45 & $10^{-0,6021}$ & 5 & $\cdots$ & $P$ & $\mathbf{P}$ & 0 \\
\hline 46 & $10^{-0,6021}$ & 6 & $\ldots$ & $P$ & $P$ & 0 \\
\hline 47 & $10^{-0,6021}$ & 6 & $\ldots$ & $P$ & $\mathbf{P}$ & NE \\
\hline 48 & $10^{-0,0601}$ & 6 & $\ldots$ & $P$ & $\mathbf{P}$ & 0 \\
\hline 49 & $10^{-0,9031}$ & 8 & $\cdots$ & $P$ & $\mathbf{P}$ & 0 \\
\hline 50 & $10^{-0,9031}$ & $\ldots$ & 21 & H & $\mathbf{P}$ & 3.200 \\
\hline 51 & $10^{-0,9031}$ & 6 & $\ldots$ & $P$ & $\mathbf{P}$ & 0 \\
\hline 52 & $10^{-0,9031}$ & 6 & $\ldots$ & $\mathbf{P}$ & $\mathbf{P}$ & 0 \\
\hline 53 & $10^{-0,9031}$ & 6 & $\ldots$ & $P$ & $\mathbf{P}$ & 0 \\
\hline 54 & $10^{-1}, 2041$ & 8 & $\cdots$ & $P$ & $P$ & 0 \\
\hline 55 & $10^{-1}, 2041$ & $\cdots$ & 21 & N & $\mathbf{P}$ & 6.400 \\
\hline 56 & $10^{-1}, 2041$ & 8 & $\ldots$ & $P$ & $\mathbf{P}$ & NE \\
\hline 57 & $10^{-1}, 2041$ & $\ldots$ & 21 & N & $P$ & 0 \\
\hline 58 & $10^{-1,2041}$ & $\ldots$ & 21 & N & $\mathbf{P}$ & 0 \\
\hline TOTAL & $\ldots$ & $20 / 25 *$ & $5 / 25$ & $20 / 25$ & $25 / 25$ & $2 / 23$ \\
\hline
\end{tabular}

GRUPO EXPERIMENTAL D = Grupo de 25 animais nảo tratados com o BCG e experimentalmente infectados

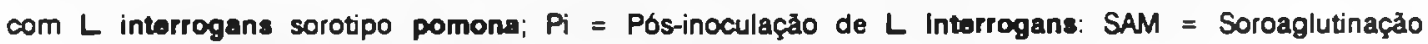
Microscópica; $\mathrm{P}=$ Positivo; $\mathbf{N}=$ Negativo; $\mathrm{NE}=$ Soro năo examinado; ... = Dado năo disponível; ${ }^{*}=$ Número de animais positivos/Número de animais examinados; = Reciproca de major diluiçăo do soro com $50 \%$ de leptospiras aglutinadas por campo microscopico. $=$ Número medio de leptospiras por campo microscopico. no inoculo puro $=31,5$. 